\title{
O MIGRANTE NOS LIVROS DIDÁTICOS DE GEOGRAFIA
}

\section{Denise Rockenbach*}

C omo professora de geografia em escolas públicas de $1^{\circ} \mathrm{e} 2^{\circ}$ graus, inúmeras vezes pude perceber de um lado atitudes preconceituosas de crianças e jovens em relação a migrantes e, de outro lado, migrantes ou filhos de migrantes que negam esta sua condição por se sentirem desvalorizados. Estes fatos pode ser analisados por vários ângulos, neste artigo procuro verificar como o migrante e a migração são abordados pelos livros didáticos de geografia, posto que estes livros comumente fazem parte do processo de ensino e aprendizagem.

O migrante aparece de forma dispersa em livros didáticos de língua portuguesa e história, mas nos livros de geografia há sempre espaço reservado para a migração. Podemos perceber na maioria dos livros didáticos de geografia uma tipologia das migrações; quanto à denominada migração interna, a migração campo-cidade (êxodo rural) é aquela que tem mais espaço, enquanto que a migração cidadecidade praticamente não é citada e a migração

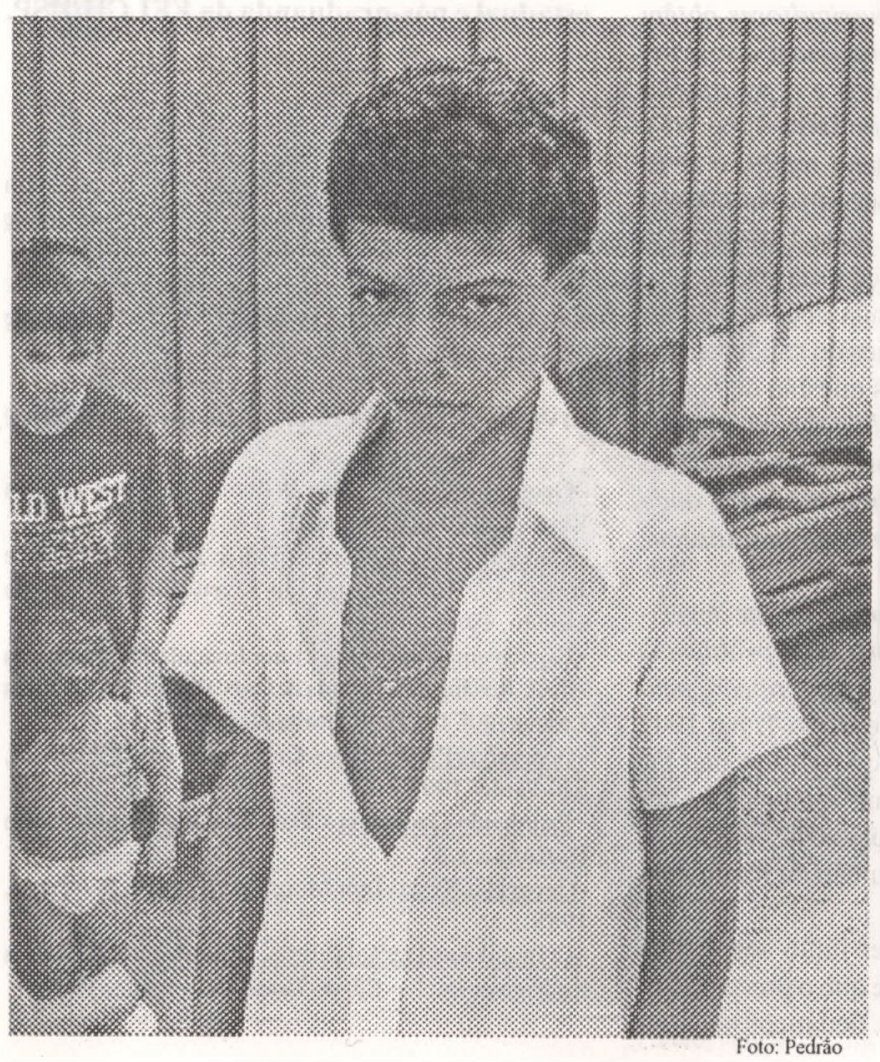

campo-campo vem ganhando algum destaque devido aos conflitos nas áreas denominadas de fronteiras agrícolas, especialmente na região amazônica.

A análise de como o êxodo rural é tratado pelos livros didáticos é particularmente relevante quando os alunos com os quais trabalhamos, residentes em cidades, trazem para a escola o senso comum de que todo migrante que veio do campo, é nordestino, pobre e fonte de problemas para as cidades. A compreensão do fenômeno migratório pode abrir perspectivas para um entendimento crítico da categoria população, que pode ser vista como algo que não é abstrato, mas permeada de diferenciações e contradições. Todavia, o que ocorre no livro didático é que o migrante não é tratado como categoria de mediação capaz de desvendar a relação campo-cidade, mas como uma pessoa atraída pelo "fascínio"' da cidade grande, pelo desejo de um modo de vida caricaturado pela TV, eliminando-se ou ignorando-se os problemas do migrante diante de um lugar diverso. Na realidade o livro didático não tem contribuído para desfazer o preconceito segundo o qual as mazelas da cidade se devem à presença domigrante, fato este que vem mascarando as contradições da sociedadecapitalista em constante processo de desenvolvimento e de suas crises, sejam elas econômicas e/ ou políticas.

Como causas do êxodo rural os livros didáticos não citam apenas causas naturais como as secas nordestinas, mas também concentração fundiária, mecanização da agricultura, Estatuto do Trabalhador. Vejamos um exemplo:

"Como a propriedade da terra está concentrada em poucas mãos $e$ os cultivos estão mecanizados, é dificil para os tra- balhadores rurais manter suas fanilias durante o ano todo. Assin, eles se deslocam para as cidades e ali permanecem temporária ou definitivamente. "(Alves, livro 2, pg. 51)

$\mathrm{O}$ fascínio que a cidade grande exerce sobre o (pressuposto) ingênuo homem do campo também é citado como causa do êxodo rural:

"As metrópoles exercen um verdadeiro fascinio sobre os homens do campo, que acreditam lá encontrar condições favoráveis de vida, sobretudo escolas para seus filhos e atendimento miédico-hospitalar. " (Vesentini, livro 2 , pg. 52)

A divulgação do modo de vida urbano através dos meios de comunicação de massa, em especial a TV, é outro motivo abordado:

"A atração que as cidades e seu modo de vida exercem sobre as populações rurais, levado principalmente pelas redes de televisão do pais. "' (Rocha, livro 2, pg. 37)

Trabalhando com alunos de $1^{\circ}$ e $2^{\circ}$ graus 0 que percebemos no que se refere ao migrante é que se por um lado compreendem e aceitam a migração devido à concentração fundiária ou à mecanização da agricultura, por outro lado não a aceitam quando o migrante vem para a cidade, em primeiro lugar, e de acordo com os textos acima, porque ele é ingênuo e se deixa iludir pelos meios de comunicação, em segundo lugar, pelas consequências desta migração, também apontadas pelos livros didáticos: 0 aumento do número de bóias-frias na periferia, aumento do número de favelados, a falta de infra-estrutura e serviços urbanos e o desemprego:

"Concentração de população nas regiões urbanas, provocada pelo exxodo rural. Este fato leva a um excesso de oferta de mão-deobra nas cidades, o que causa um decréscimo no nivel médio de renda da população, aumentando o desemprego e o múmero de favelados. A qualidade de vida para boa parte da população torna-se, assim, precária." (Antunes, livro $2, \mathrm{pg} .37$ )

O êxodo mural descontrolado do campo para a cidade provoca uma desorganização na estrutura urbana." (Marcio, volume 4, pg. 130)

O textos acima transformam as pessoas que migram para as cidades em responsáveis não só pela sua própria condição de pobreza, mas por todos denominados " problemas urbanos" 
gerando/aprofundando preconceitos. Questões políticas e econômicas a respeito do planejamento e administração das cidades não são colocados em xeque, aponta-se as consequências da migração para a metrópole como um "problema social" onde não existe a questão política.

São poucos os exemplos nos livros didáticos de geografia, como no caso abaixo, que parecem entender a mão-de-obra migrante e questionam o governo a respeito da falta de infraestrutura para esta população, embora deixe a impressão de que o problema das contradições de classe se resolvem apenas em nível de Estado:

"O grande afluxo de trabalhadores, particularmente do nordeste, em direção ao sudeste, forneceu mão-de-obra abundante e barata para as industrias. O governo que tanto estimulo deu ao desenvolvimento industrial, criando infra-estrutura de transportes e energia, não acompanhou a crescente demanda por habitação, saneamento básico e educação que o êxodo mural e a urbanização exigiam. As favelas cresceram nas cidades. " (Gonçalves, volume 2 , pg. 118)

Para a maioria dos livros didáticos o migrante é uma "fonte de problemas para as cidades", sua importância enquanto mão-de-obra barata, exército industrial de reserva ou mercado consumidor não são abordadas. Todavia, o capitalismo precisava, como ainda precisa do migrante, "dos adultos ocupados, entre março e janeiro de 86, na Grande São Paulo, aproximadamente $62,3 \%$ eram migrantes. Formou-se, então nas cidades, o grande exército excedente de mão-de-obra barata à disposição do capital.

As condições em que essa mão-de-obra vai sobreviver e se reproduzir na cidade não interessam ao capital. É um problena que cabe à cidade e à sociedade como um todo (...). $O$ objetivo é fazer crer que toda a crise social urbana, consubstanciadanas péssimas condições de vida a que está condenada a classe trabalhadora, nada tem a ver com o sistema de produção, que utiliza e remumera tão injustamente tal classe. "(1)

Um outro ponto que nos chama atenção na forma pela qual os livros didáticos abordam a migração é a ênfase na migração nordestina. Em alguns casos a migração só é abordada no capitulo que se refere à região nordeste, como se a problemática da migração fosse exclusiva aos nordestinos:

"À medida que a população migrante nordestina se oferece dentro da região como mãode-obra excedente, nas indístrias, no comércio e nos serviços, faz baixar os niveis de salários, uma vez que a oferta de empregados passa a sernaiorque onimerode empregos". (Alves, livro 2, pg. 52)

Embora a migração nordestina para o centrosul seja de fato bastante expressiva, isto não significa que sejam os nordestinos os únicos a desembarcar na estação rodoviária de São Paulo, nem que sejam os nordestinos os únicos a formar a massa de desempregados na metrópole paulista. O exemplo acima é um clichê que muitos de nossos alunos trazem para a escola e que passa a ser reforçado pelo livro didático.

As migrações além de não serem abordadas em sua essência pelos livros didáticos são vistas só no seu lado negativo e não como oportunidade de "construção" de algo novo na vida dos migrantes, representando uma importante transformação social. Mas é estranho se notar que a migração campo-cidade é vista em seus aspectos negativos apenas nos países do Terceiro Mundo, no caso abaixo o autor escreve a respeito das migrações na Europa Ocidental:

"As atividades agricolas nos paises industriais tornaram-sé cada vez mais modernizadas, com o emprego de novas técnicas e novos meios de produção. Geralmente, a modernização do camipo provoca dimimuição da oferta de empregos, pois as máquinas não exigem muitos trabalhadores para operá-las. Consequentemente, muitos deles precisam mudar-se para as cidades, em busca de emprego.

Geralmente, os antigos agricultores obtêm emprego nas cidades, onde passam a residir. Com isso, as cidades crescem e a população urbana aumenta. " (Moreira, livro 4, pg. 43)

Por vezes em um pequeno trecho o livro expressa não apenas preconceitos em relação ao migrante, como se ele fosse causador do desemprego, da insegurança e da miséria na cidade, como também veicula noções equivocadas como se a problemática do subdesenvolvimento fosse uma simples questão de opção:

"A maior concentração da pobreza está nas áreas rurais e os movimentos migratórios transferem esta pobreza para as cidades, onde aumentam os indices de desemprego, insegurança e miséria.

Muitos paises subdesenvolvidos, que deveriam buscar as soluções para seus problemas nas atividades agrícolas, fazem opção pela industrialização. "'(Marcio, livro 4, pg. 104)

Neste texto verificamos que o autor não faz menção às relações de dominação-subordinação existentes na base da sociedade capitalista que se expressa na distribuição de renda e no acesso ao solo urbano.

$\mathrm{O}$ que pudemos perceber junto aos alunos com os quais trabalhamos é que o preconceito, explícito ou não, dos livros dedáticos não tem contribuido para levar os alunos a superar preconceitos e uma posição de repúdio em relação aos migrantes.

Como se sentem alunos migrantes ou filhos de migrantes diante destas noções veiculadas pelos livros didáticos? Discriminados, com certeza, e muitos até passam a negar sua identidade. As experiências que o aluno tem po$\mathrm{dem} /$ devem ser resgatadas pelo professor como possibilidade concreta para desencadear um processo de conhecimento se não quisermos manter nossos alunos calados, passivos, engolindo as informações que o livro didático despeja sobre eles e lhes é exigido de volta nas provas. O conteúdo a ser trabalhado na sala de aula deve ser um elemento mediador entre a realidade do aluno e o conhecimento sistematizado, faz-se necessário confrontar o conteúdo do livro didático com a vida dos alunos para não desencadear/acentuar o que nos relata Sposito: "Na verdade, precebe-se hoje que os migrantes aprenderam em suas estratégias de sobrevivência, por contingência, a separaros 'saberes' e a ter expectativas diversas em torno de cada um. Espera-se que o saber da escola' instrumentalize para a profissão, para o trabalho e dé 'diploma'. Já o saber da vida e da luta social é diferente, ele o insere na história e mostra que existe a possibilidade da transformação": (2)

* Denise Rockenbach é Professora da rede estadual e pós-graduanda da FFLCH/USP.

\section{NOTAS}

(1) Fechio, Fermino - Migração e Violência: quem tem medoda asa branca? - In Travessia-Revista do Migrante n. 2 - CEM, São Paulo, set/dez 1988, pp.22-23.

(2) Sposito, Marilia Pontes - O Migrante e a Educação: o sonho nutre a luta - In Travessia-Revista do Migrante n.2 - CEM, São Paulo, set/dez 1988, pg.20.

\section{LIVROS DIDÁTICOS ANALISADOS - $1^{\circ} \mathrm{GRAU}$}

- Geografia Critica - José William Vesentini e Vânia Vlach, Ed. Ática, São Paulo, 1991

- Geografia Hoje - Carlos Walter Porto Gonçalves e Jorge Luiz Barbosa, Ed. ao Livro Técnico, Rio de Janeiro, 1988

- Espaço em Construção - Luci Imaculada de Oliveira Alves, Rosângela Miranda de Carvalhoe Idária Esteves Lasmar, Ed. Lê, Belo Horizonte, 1990

- Geografiae Participação-Celso Antunes, Ed. Scipione, São Paulo, 1991

- Estudando Geografia - David Marcio, Ed. Lê, Belo Horizonte, $s / d$

- Geografia Nova-Igor Moreira, Ed. Ática, São Paulo, 1988

- O Brasil e as Desigualdades Regionais - José Carlos Rodrigues Rocha, Ed. do Brasil, São Paulo, 1987 